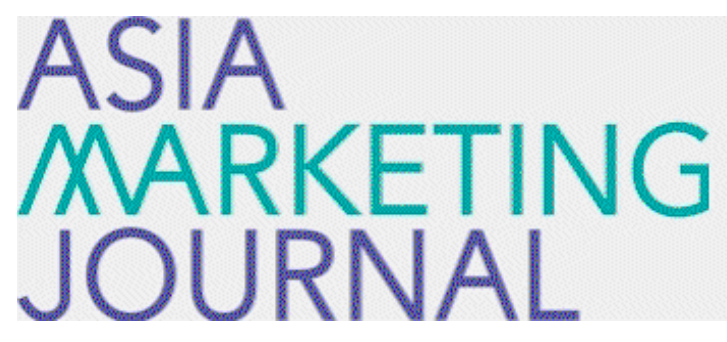

ASIA MARKETING JOURNAL

Volume 20 | Issue 4

Article 4

$1-31-2019$

\title{
Labeling and Customer Loyalty
}

Zheltauova Gulzira

Sang-Lin Han

Follow this and additional works at: https://amj.kma.re.kr/journal

Part of the Marketing Commons

\section{Recommended Citation}

Gulzira, Zheltauova and Han, Sang-Lin (2019) "Labeling and Customer Loyalty," Asia Marketing Journal: Vol. 20 : Iss. 4 , Article 4.

Available at: https://doi.org/10.15830/amj.2019.20.4.65

This Article is brought to you for free and open access by Asia Marketing Journal. It has been accepted for inclusion in Asia Marketing Journal by an authorized editor of Asia Marketing Journal. 


\title{
Labeling and Customer Loyalty: Mediating Effects of Brand-related Constructs
}

\author{
Zheltauova Gulzira* \\ Sang-Lin Han**
}

The purpose of this study was to analyze the brand loyalty formation by positive labeling. Affecting such factors as involvement, self-image, community engagement, preference, and choice cutback, positive labeling can be seen as one of psychological factors that shapes consumer's behavior and their decision.

This study was carried out because little research was done to examine the influence of positive labeling toward brand loyalty, and also to find out the benefits that consumers can get from being labeled in positive terms.

Data were collected through survey questionnaire and 151 usable responses were used. Following a series of pretests and confirmatory factor analysis helped to purify measures and verify the psychometric properties of the scale. Structural equation modeling with AMOS was used for testing of research hypotheses.

The result of data analysis demonstrated the positive relationship between labeling and brand loyalty, i.e. positive labeling indirectly leads to consumers' loyalty toward a brand. Findings revealed significant relationship between involvement and emotional attachment, as well as the relationship between community engagement and choice cutback. The results gave support for the hypothesis of moderating effect of buzz on the relationship between involvement and emotional attachment, even though the hypothesis of moderating effect of distinction was rejected.

Taking Apple's rivalry strategy as initial point, this study highlights the role of labeling in creating social identity. The study attempts to show the positive consequences of labeling strategy for firms that seeks ways of good competition without engaging into conflicts.

Key words: Positive labeling, brand loyalty, buzz, communication, choice cutback

\footnotetext{
* Graduate School, Hanyang University

** School of Business, Hanyang University (slhan@hanyang.ac.kr), Corresponding Author
} 


\section{Introduction}

Consumer loyalty plays as a key factor in business success of firms in competitive markets, and much studies have examined the various factors that motivate consumers to remain loyal to a company's product. Previous researches on consumer loyalty have mainly examined concepts such as service quality, price, perceived value, customer satisfaction, and trust as antecedents of loyalty. Butcher (2001) and his colleagues describes these antecedents as evaluative judgment variables, while Lai (2009) and others highlight them as service evaluation factors determined primarily through consumers' evaluation of the actual service experience. Thus, from this perspective, consumer's loyalty toward specific product or brand depends on the consumer's assessment of the consumption with that product or brand. Accordingly there remains a gap for the researches on individual psychological factors and social influences on consumer loyalty. This study attempts to fill this gap by examining the impact of labeling toward consumer loyalty through psychological outcomes of a person and his behaviors.

In the 2017 Customer Loyalty Engagement report Apple was recognized as the best representative of customer loyalty and enjoyment. The loyalty of Apple customers is not a new phenomenon, it dates to their earliest years. Apple's survival and popularity through challenging times of low market share and management mistakes is due to it was never abandoned by its customers. Many factors made this loyalty - brilliant design, original products, creative marketing, and etc. But more importantly the key factor is that they created strong PR by making an enemy and dividing market audiences into groups. Apple attacked the PC users themselves, and drew a sharp distinction between Mac users and everyone else, while other brands paid all attention on product characteristic, such as performance, price, ease of use, etc. In nowadays market there is no need for a company to make an enemy of a brand. Instead of rallying cries that criticize a competitor and hurting company's reputation, it is better way for a firm to create social identity of customers through positive labeling.

According to Labeling Theory people tend to act in accordance with the labels that others assign to them. When a person is assigned a label they tend to view themselves and act in such a way that promotes them to be labeled in that way.

A simple example of this can be made with the birth. As soon as a baby is born, he or she is put onto expectations with labeling as boy or girl. With this tagging most things would be determined, from what color of clothes he/ she will wear on to the type of professions they are accepted to choose. Typically labeling theory is associated with negative consequences, and usually revolves around deviance, but there is 
also positive labeling, which we use and willingly bestow on ourselves and others, because they describe attributes that we all seek. And again there are not much enough studies made on positive labeling and its outcomes. Some researchers found out that people do like being labeled when it implies some sort of characteristic, positive human goal, or worthwhile achievement.

\section{Theoretical Background}

\subsection{Loyalty}

Loyalty is noble. It suggests that a person has a conviction, trust, and fidelity. But this aside, maintaining loyalty is easy, it is the tried and true. Consumers weary of consuming can repurchase without great effort, provided the consumable has not changed for the worse. Consumer loyalty is the result of consistently positive emotional experience, physical attributebased satisfaction and perceived value of an experience, which includes the product or services.

The concept of loyalty emerged in the marketing literature in the 1940s (RundleThiele, 2005) and since then has received much attention. Oliver (1999) defined loyalty as a deeply held commitment to repurchase a preferred product or service consistently over time, despite situational influences and marketing efforts that might have the potential to cause switching behavior. He classified loyalty into four types: 1) cognitive loyalty - a loyalty based on brand belief only; loyalty toward the brand is based on prior or vicarious knowledge or on recent experience-based information, 2) affective loyalty - a liking or attitude toward the brand has developed on the basis of cumulative satisfying usage occasions, 3) conative loyalty - influenced by repeated episodes of positive affect toward the brand, and 4) action loyalty - the motivated intention in the previous loyalty state is transformed into rediness to act. Over the years, two broader brand loyalty dimensions have developed - attitudinal loyalty, which means measuring consumers' purchase intention and overall feelings about brand, and behavioral loyalty, which is often considered synonymous with repeat purchase behavior. Other researchers, such as Pederson and Nysveen (2001), have suggested composite measures of loyalty, arguing that loyalty is formed both by the customer's attitude and behavioral intentions and it should be measured as a combination of attitudinal and behavioral dimensions..

Among the academic and professional fields, interest is growing in identifying the factors that influence customer loyalty with developing the most appropriate market action strategies (Bendapudi \&Berry, 1997; Dick \& Basu, 1994; Gustafsson, Johnson \&Roos, 2005). The brand marketing efforts deployed by marketers in convincing consumers about such attributes consequently become a vital attempt to win 
and influence consumer loyalty. Keller (2013) by suggesting approaches to brand-building via four major processes of designing and implementing, brand marketing efforts. He compromised the use of brand identities, incorporating marketing programs, integrating marketing communications and leveraging secondary associations. But from the customer perspective, customers are loyal because they really wish to maintain the relationship (FuentesBlasco, Saurab, Berenguer-Contri \&MolinerVelazquez, 2010). Thus, Schwartz (1994) in his work on provides that human values are the foundation of individuals' thoughts and behaviors, and these values strengthened by personal experiences can be used to measure or evaluate particular objects. But each individual's standards are unique, so when a firm's product or service matches an individual's personal values, that person is likely to evaluate the company more positively. Hence there is a need to investigate psychological factors affecting consumer behaviors for brand choice, specifically their loyalty favoring firm's product.

\subsection{Labeling}

As Lemert described in his work on social pathology (1972) "by labeling we usually mean that the identity ascribed to an individual is in some respect deliberately altered to his discredit because of an alleged deviation. Stigmatization describes a process attaching to persons, such as invidious labels, marks, brands, or publicly disseminated information."

According to Becker (1963) labeling theory is based on the notion that certain members in society have the ability to construct and apply attributes to other members of the same society. The application of a label is often negative, from one societal group to another result in the creation of an "other" and thus the individual or group to which the label has been applied is stigmatized and considered to be outside of conventional society (Akers \& Sellers, 2009).

Kowner (1998) differentiated labeling into two types as abstract labeling and concrete labeling. Abstract labeling is a categorizing process people conduct on an imagery target. Abstract labeling only concerns targets that cannot be sensed during the process of labeling. When this type of labeling is used in experimental procedure, it denotes that subjects are instructed to imagine target persons and to rate them on various measures. Concrete labeling is a categorizing process people conduct on a concrete target-person. Concrete labeling concerns targets that can be sensed to a various extent during the process of labeling. When this type of labeling is used in experimental procedure, it denotes that subjects are instructed to rate target persons with whom they have physical contact, or at least a concrete representation of that person. The author makes some important differences between abstract labeling and concrete 
labeling. People conducting abstract labeling are focused on the label rather than on personal features. Because they deal with a schema of a particular group and only few competing representations can disrupt their response, they tend to assess the features in question in extreme terms. When conducting concrete labeling, people are exposed to perceptual images of individuals rather that individuate images of a whole group.

There are three major theoretical directions to labeling theory. They are Bruce Link's modified labeling, John Braithwaite's reintegrative shaming, and Ross L. Matsueda and Karen Heimer's differential social control.

In 1989, Link's modified labeling theory expanded the original framework of labeling theory to include a five-stage process of labeling as it pertained to mental illness. The stages of his model are (1) the extent to which people believe that mental patients will be devalued and discriminated against by other members of the community, (2) the time period by which people are officially labeled by treatment agencies, (3) when the patient responds to labeling through secrecy, withdrawal, or education, (4) the negative consequences to this individual's life that were brought about as a result of labeling, and (5) the final stage of vulnerability to future deviance as a result of the effects of labeling.

The theory of reintegrative shaming, introduced by John Braithwaite in 1989, examines the difference between stigmatization of the individual and reintegrative shaming, or encouragement to stop the behavior without labeling and stigmatizing the individual in society. This theory essentially posits that reintegrative shaming will reduce crime, unlike stigmatization, which, according to labeling theory, essentially increases it by encouraging future deviance. The framework behind this theory is that individuals, after committing an act deemed as criminal or delinquent, will be shamed by society for that act and then reaccepted back into society without a permanent label of "not normal," "deviant," or "criminal." Furthermore, a second concept of this theory is the notion of restorative justice, or making amends for wrong actions with those who were affected by the behavior. The argument driving this theory is the notion that reintegrative shaming demonstrates that a behavior is wrong without hurting the individual accused of that behavior. Rather, society encourages the individual to make up for what he or she has done, show remorse for the choice of behavior, and learn from the mistake. Under this theory, society teaches its members and then readily accepts them back into the group without permanent labels or stigmas attached.

Matsueda and Heimer's theory, introduced in 1992, returns to a symbolic interactions perspective, arguing that a symbolic interactions theory of delinquency provides a theory of self- and social control that explains all components, 
including labeling, secondary deviance, and primary deviance. This theory relies on the concept of role taking, a concept that illustrates how individuals reflect on their behavior, how they are able to put themselves in the shoes of others in order to view the situation or behavior from the other's standpoint, and how they evaluate alternative actions that would be more acceptable and not seem as inappropriate in the eyes of others. Heimer and Matsueda expanded this notion to include the term differential social control, which emphasizes that social control through role taking can take a conventional direction or a criminal direction because the acceptable courses of actions by peers may not necessarily be conventional or nondeviant courses of action.

Labeling theory is situated within the symbolic integrationist framework which suggests that one's identity and self-concept are continually defined by interactions with others, and thus only exist based on social interaction (Akers \& Sellers, 2009). As a result, it can be surmised that those individuals who are negatively labeled will integrate this label into their perception of self.

\subsection{Involvement}

Research into consumer involvement is varied, ranging from descriptive case studies to cross sectional surveys and covering many approaches and many types of products, development contexts, and firms (Chan et al., 2016, Kujala, 2003).

Involvement can be defined as a person's perceived relevance of an object based on his/ her needs, values and interests (Zaichkowsky, 1985). The historical roots of the involvement construct can be found in social psychology, dating as far back as 1947 when the construct first mooted, it was not until the mid-1980s when researchers began to understand the importance of studying the construct for the purpose of segmenting markets (Lesschaeve \& Bruwer, 2010). The involvement construct has since then, received much attention due to its significant influence on consumer information processing and purchasing behavior (Lee \& Lou, 1996).

Cabanero (2006) noted three main dimensions of involvement: intensity, address and length. Intensity relates to the level of consumer perceived involvement which is totally subjective for each person and to a particular degree or level. Meanwhile involvement address relates to the stimulus producing that perception: it can be a product category either tangible or intangible, a particular product or brand, and advertisement, a purchase decision or even a current political issue (Rifon \& Trimble, 2003). And length refers to timing and there are two types: enduring involvement and situational involvement, which is shorter. Enduring involvement is related to the values and the self-concept of the person to a product category independently 
of a particular purchase decision. Situational involvement includes purchase involvement because its interest and concern is considered perishable (Mittal, 1989).

Involvement seems to be vague concept since it is interrelated with diverse concepts and meanings. Therefore, it has been used as an umbrella term which many similar but different vocabularies have been used to describe it and it is widely applicable in other disciplines as well. However, in marketing consumers are considered to be people involve with different advertisements and advertising media, products and products range and purchase decision as well. Although there is no precise definition of involvement in marketing, there is a consensus that involvement is a personal level and intrinsic variable which returns to the importance and personal attachment of goals or events (Abdolvand \& Nikfor, 2011).

\subsection{Emotional Attachment}

Attachment theory in psychology originates with the work of John Bowlby (1958) He described attachment as a deep and enduring emotional bond that connects one person to another across time and space.

Emotional attachment is often described as "an emotion-laden target-specific bond between a person and specific object (Thomson et al., 2005). Scholars generally view emotional attachment as a basic human need that occurs naturally and unconsciously (Ainsworth et al., 2014; Crowell et al., 2008; Thomson et al., 2005). Most marketing researchers concludes that emotional attachment occurs as beyond one's volitional control, which distinguishes it from other relevant concepts including loyalty and involvement, which imply cognitive decisions (Thomson et al., 2005). As many studies on attachment show that people could have strong ties with variety of objects, but people are particularly prone to becoming attached to consumer products (Mugge et al., 2009; Schifferstein \& Zwartkuis-Pelgrim, 2008; Slater, 2001).

Thomsan et al. (2005) argue that brand love, brand connection and brand affection strengthens a customer's emotional attachment. Park et al. (2010) revealed the practical value of emotional attachment in marketing where emotional attachment was setup to be enhanced forecaster of brand purchase share, actual purchase and brand need than brand attitude.

\subsection{Community}

Belonging to a community is more than a luxury - it is a fundamental need. Community is a complex and difficult web of human relationships within varying environments, and the importance of understanding such phenomena has been noted within sociology, ecology, psychology and marketing. Fowler and Krush (2008) defined community as a structured and inter-related 
network between groups of people where each individual group as well as the collective network of groups is bound together by relations that may include affect, loyalty, common values, personal concerns, common activities, and beliefs and where the tie strength of relationships within groups is relatively greater than the tie strength that exists between group.

According to McAlexandr et. al(2002) community is instrumental to human's wellbeing and can be formed around diverse elements, such as a neighborhood, an occupation, a leisure activity, or devotion to a brand. Brand community is used to describe like-minded consumers who identify with a particular brand and share significant traits. The idea of a brand community or a community built on the consumption of a commercial brand has been widely revised by different authors.

Brand communities have three common characteristics: 1) an intrinsic connection such that members feel different from others not in the community, 2) the presence of shared rituals and traditions that perpetuate the community's history, culture, and consciousness, and 3) a sense of moral responsibility, duty, or obligation to the community as a whole and its individual members. These characteristics indicate to us that members are willing to act collectively to protect and promote the community under the shelter of a brand (Muniz \& O'Guinn, 2001).

Brand community brings value not only to the consumer, but also to the brand. Consumers who show a genuine interest in the brand will be credible and have success in persuading toward and bonding other customers with the brand, leading them to make repeated purchases and to feel loyalty (Bagozzi \& Dholakia, 2006). A brand-based community may also function as an aspirational group for current non-users of the brand as well as an information source for potential users. Marketers would be provided with a customer base that is both highly involved with and highly committed to the brand McAlexandr et al., 2002).

\subsection{Choice cutback}

Oxford dictionary gives definition for the word "cutback" as an act or instance of reducing something, especially expenditure. And the word is often used for management terms, when local and state governments close their budget deficit during recessions. And it addresses processes and strategies used by policymakers when their organization faces a situation of resource scarcity. In marketing area this term can be used as a strategy against choice overabundance.

Economic and theories suggest that having more options is preferable to consumers, because it increase the profitability of choosing options that maximize utility (Benartzi \& Thaler. 2001). Having more options has also been consistently considered beneficial from the perspective of psychology as well. Sometimes, too much of a 
good thing is just too much.

Iyengar and Lepper (2002) presented that having more options causes negative consequences. Other scholars found out that over-abundance of choice within a category is likely to make the choice more difficult, as the differences between attractive options are smaller and the amount of available information increases (Fasolo et al., 2007; Timmermans, 1993). Further, large assortments, make an exhaustive comparison of all options seem undesirable from a time and effort perspective. In turn, this could induce the fear of making a less than optimal choice (Iyengar et al., 2006; Schwartz, 2004). The attractiveness of the second-best, non-chosen alternatives is also likely to be greater in large assortments. This could lead to more counterfactual thinking and regret concerning options that were not chosen. Large assortments may also increase expectations. If the available options are all very similar these expectations may not be fulfilled (Diehl \& Poynor, 2010; Schwartz, 2000).

\subsection{Buzz}

Buzz marketing is a part of a communication process between a company and a customer, which is defined as the amplification of initial marketing efforts by third party through their passive or active influence. Servovitz (2011) used the given term to construe the process of providing consumers with topics of conversation relating to the company's offer and skillful prompting of this kind of communication. Buzz marketing is conscious marketing activities aimed at reaching consumers in a direct way, and triggering positive associations with the brand or product (Rosen, 2008). The essence of buzz marketing is spreading information, which is based on interpersonal contacts and thus perceived as reliable, true and verified. Products and brands recommended by friends or family are more trusted and more probable to be purchased. A message sent by a wellknown trustworthy person is more effective than other kinds of marketing, including advertising.

Pilarczyk (2011) classifies buzz marketing into two dimensions - face-to-face marketing or live buzz marketing as specified (Mohr, 2007), and on-line buzz marketing. Face-to face buzz marketing defines information and messages are passed on through direct contact, getting people talk about particular product, brands or trends in a particular environment aimed at boosting sales (Pilarczyk,2011). On-line buzz marketing refers sending information and messages through the Internet or mobile devices. In turn live buzz marketing could be divided into two types, as live peer-to-peer marketing, where ordinary consumers are encouraged to convey word of mouth about a product, service, or brand and includes brand advocacy, product seeding, or brand ambassador; and live performer-to-peer marketing, which involves the use of trained, qualified performers 
who take on the role of brand advocates in specific settings where target consumers are likely to be found (Foxton, 2006)

\subsection{Self-image}

A substantial amount of research in social psychology suggests that people are motivated to maintain a positive view of the self (Sedkes, 1993; Taylor \& Brown, 1988). Some scholars showed that people rate positive personality traits as more descriptive of themselves than of others of themselves (Miller \& Ross, 1975; Taylor, 1983). People tend to see themselves as being better than average in various domains of life. Examination of a survey of college professors conducted by Cross (1977) provided result where $90 \%$ of them believed that their work was better than average. Other research found that a majority of people believe they are better than average in terms of driving ability, personal health, and managerial skills (Svenson, 1981; Weinstein, 1982; Larwood \& Whittaker, 1977). Because it is logically impossible for a majority of people to be better than average, these flattering self-evaluations are indicative of people's tendency to maintain a positive view of self.

In sum, self-image is not something that is based on reality, actually a person's self-image is built upon his or her perception of reality and that is influenced by how he/she believe themselves being viewed by society and other people. It develops over a lifetime of experience through learning and societal influence, and changes over time as person gain more life experience. Self-image is not only one's holistic view or emotions about oneself, but also is a decisive factor or criteria human behavior. Shaped by society emotions affects a person's decision-making process in purchase.

\section{Research Model and Hypotheses}

\subsection{Research Model}

The following research model (Figure 1) consist of Labeling as independent variable, brand loyalty as dependent variable, and as mediating construct involvement, self-image, community engagement, buzz, emotional attachment, preference, choice cutback, and distinction.

\subsection{Research Hypotheses}

In most studies and literatures labeling is posited to have negative consequences for a person who is tagged. For example, the study conducted by Adams and his colleagues (2003) provided support for labeling theory. Proving with the study result that teachers and peer groups are important sources of negative labels which can lead to the adoption of a deviant self-concept, they concluded that perceived 
〈Figure 1〉 Conceptual model

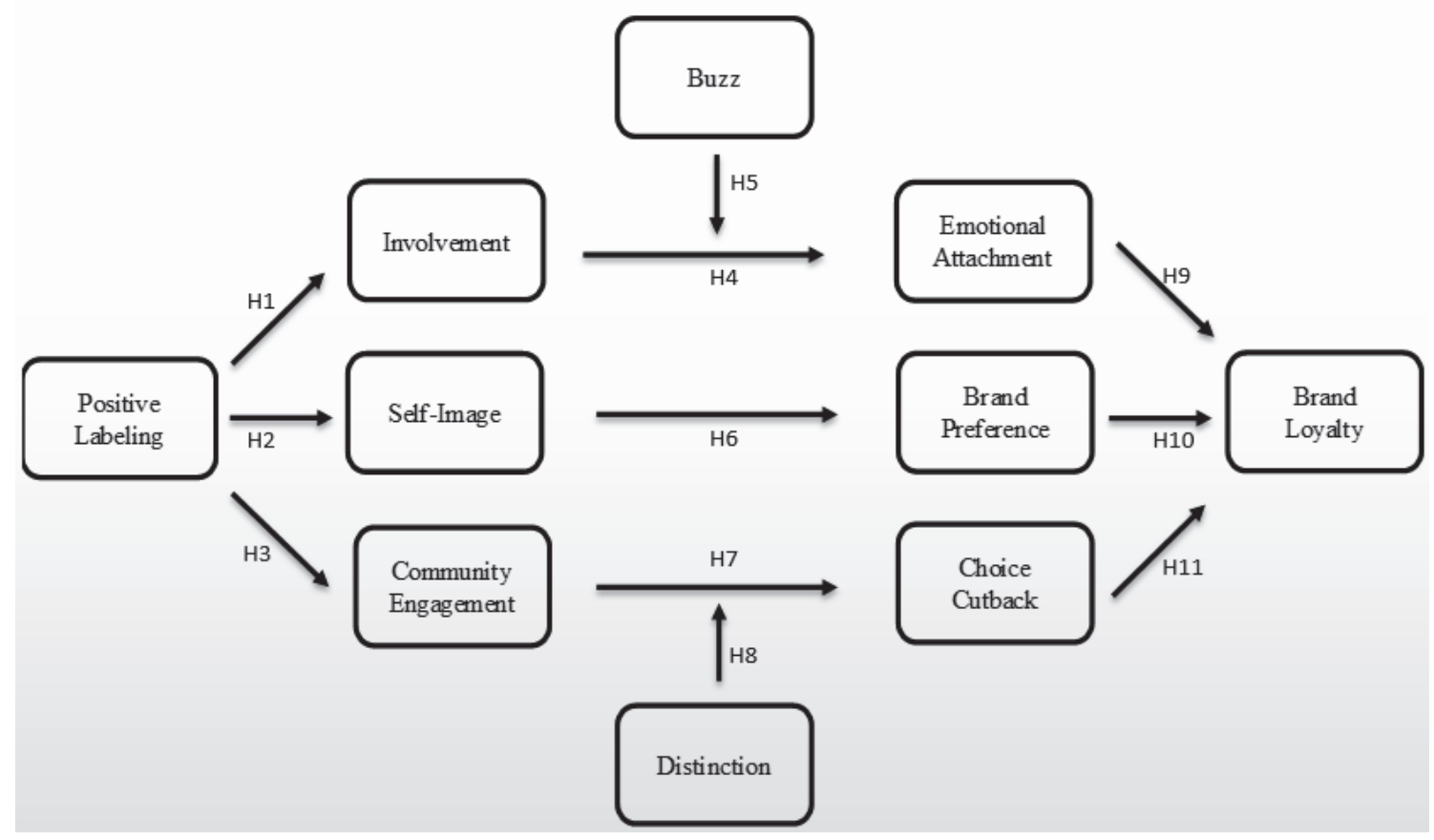

negative labels were related to increased involvement in self-reported delinquent behavior. Kavish's (2012) findings support previous scholars' claims that labels can indirectly influence subsequent delinquency and suggest that negative reflected appraisals may significantly influence future delinquency involvement directly, though there may be a change in identity for some individuals that have been formally labeled. Indicating formal labeling measured by selfreported arrest the study results highlight, even having small effect that is statistically significant suggests that formal labels matter. Hence, one of the possible responses to being stigmatized or negatively labeled is involvement in delinquent behavior
Garcia (2013) Examined youth violence of incarcerated juveniles and inner-city high school students in the states of California. The research effectively used the answers from the survey to evaluate the relationship between internalization and deviance. As it was hypothesized the more an individual internalizes negative labels, the more likely it will have an effect on the level of deviance an individual will potentially participate in.

In particular, labeling theorists have largely overlooked the possible effects of positive labeling. The reason is the effects of negative labeling are relatively easy to see. But some labeling theorists have assumed that while negative labeling can backfire and exacerbate problem 
behavior, positive labeling fosters conformity and therefore is not of criminological concern. An example can be provided by Matsueda (1992) who recognizes the significance of positive labeling: "...labels are not restricted to deviance. One can be labeled a conformist or a success at conventional activity, which should increase the likelihood of conventional behavior, while decreasing the likelihood of deviance".

The social identity framework offers an underresearched avenue in the labeling debate. It suggests that labeling produces "in-groups" and "out-groups", influencing the self-esteem of those affected (Abrams, 1990). Early social identity theory was primarily concerned with group behavior when a social identity was clearly used over an individual's identity, as in a crowd situation (Hogg \& McGarty, 1990, Turner, 1987).

Social identity theory suggests a person's self-esteem comes from group membership, and therefore, alters people's behavior during collective action (Mone et al., 1995). Because social identity forms the basis for group adherence and individual actions, self-categorization and individual's social identity in a position to influence behavior through other self-referent constructs. For example, disability labels produce a social identity (in-group) through self-categorization. In turn, those in-group members (others with the same label) will be perceived as more similar, through social projection, and therefore, provide a superior modeling influence on an individual's self-efficacy.
In sum, social labels create expectancies or activate prior beliefs that, in turn, often lead people to assimilate their judgments to the label provided. Hence, hypotheses 1, 2 and 3 are as follows:

Hypothesis 1: Positive labeling leads to consumer involvement.

Hypothesis 2: Positive labeling leads to consumer's positive self-image

Hypothesis 3: Positive labeling leads to community engagement.

Customer involvement is a concept that is being explored as a tool to facilitate predictive power of customer behavior including loyalty and referrals (Roderick \& Brodie, 2011). Past research shows that consumers with heightened levels of interest or involvement are more likely to exhibit intensified levels of engagement.

Vivek (2012) and colleagues in their work on customer engagement argued that it is composed of cognitive, emotional, behavioral, and social elements. They offered a model where the participation and involvement of current or potential customers serve as antecedents of customer engagement. And made a conclusion that cognitive and emotional element of consumer engagement incorporates experiences and feelings of individuals, irrespective of the exchange; and the behavioral and social elements capture the participation by individuals with the brand or product both within and outside of the 
exchange.

In the other work Hollebeek et al. (2014) by developing and validating consumer brand engagement scale in specific social media settings, conceptualized consumer engagement as a consumer's positively valenced brand-related cognitive, emotional and behavioral activity during or related to focal consumer-brand interactions. And found that consumer brand involvement has a positive effect on the three dimensions (cognitive processing, affection and activation) of consumer brand engagement.

In addition, research conducted by Wirtz et al. (2013) on online brand communities agrees that consumer engagement increases as the level of consumer involvement with the brand intensifies. Characterizes involvement he posits that brand often elicits high levels of involvement, loyalty and emotion among members; members are frequently motivated to help others, wanting to feel connected. Thus, it is hypothesized that:

Hypothesis 4: Consumer involvement has a positive effect on emotional attachment.

It is well known that customers are affected by people from their immediate environment when they make purchase decisions. According to research result on buzz marketing (Sorokin, 2012), the decision process referring to buying fast-rotating products (mainly foodstuffs) family members and friends are most influential. The research conducted in the same group of respondents concerning purchase of bigger value (such as car or computer) has shown that $32 \%$ of consumers ask their immediate environment for recommendations.

Another example can be made by study Mohr (2007), where he portrayed the case of the movie "My Big Fat Greek Wedding”; marketers first targeted Greek-Americans at parades around the nation and employed an e-mail campaign directed at people of Greek heritage. Buzz spread via free merchandise and through previews screenings, held in Greek communities for associated festivals, churches, and other organizations. Due to the approachable humor it portrayed, the movie was appealing to a wide audience, and thus easy to grow beyond the Greek community market segment. With each passing week, positive buzz expanded the film's run to new screens and new market segments nationwide, attracting bigger audiences.

Thomas (2004) defining buzz marketing as the amplification of initial marketing efforts by third parties through their passive or active influence, argues the ultimate buzz is delivering exceptional value, what is known as the relative advantage of the offer. When this is achieved, the offer itself will be the buzz. In creating exceptional value, Thomas stresses the importance of integrating customers into the process of product development, with the objective of surprising buyers with added or unanticipated value. This, in turn, evokes customer delight, an emotional response which results in the 
highest levels of customer satisfaction, higher retention rates (customer loyalty), and higher buzz levels. Buzz marketing campaigns are intended to attract the attention of consumer targets with content that is likely to arouse short-term as opposed to enduring involvement and to create an effect that is more emotional and experiential in orientation that suggestive of need satisfaction (Kirby \& Marsden, 2006).

Hence, it is hypothesized that:

Hypothesis 5: Buzz positively moderates the relationship between consumer involvement and emotional attachment.

Healthy self-image is built upon the strong foundations of a high level of self-worth. Products help to define and maintain consumers' self-concept by reinforcing their identities. According to Graeff (1996), self-image is positively related to customers' product evaluations and triggers motives that create the need for self-consistency and self-esteem. The interaction between the image of the product user in various media and consumer's self-concept results in the consumer striving for self-image congruence.

For example, products that are labeled "healthy" are being marketed as new retailers and new brands vie for the consumers' share of wallet. Consuming healthy food is seeing an upsurge all around world. It has become "cool" to be seen as being a health conscious consumer, and a key motive in the purchase of organic food
(Grankvist \& Biel, 2001). Marketers are responding to these changed preferences by increasingly selling products labeled "healthy" (Leeflang \& Van Raaiju, 1995).

Scholars have consistently identified a significant effect of self-image in consumption decisions. Consumer's sense of self influences preference toward products or brand that help maintain their self-image threats encountered in the environment. And people tend to purchase products and services that are consistent with the image they would like to project (Line \& Hanks, 2017). Thus, it is hypothesized that:

Hypothesis 6: Self-image has a positive effect on consumer preference toward a brand.

In Rapport's (1998) work community was considered to be a concept of always positive evaluation and evocation, whose usage expresses and elicits a social group and a social environment to which people would expect, advocate or wish to belong.

Bagozzi and Dholakia (2006) pointed that a small group brand community is a friendship group of consumers with shared enthusiasm for the brand and a well-developed social-identity, whose members engage jointly in group actions to accomplish collective goals or to express mutual sentiments and commitments.

The best example for the theory that community engagement limits consumer choice can be seen through football fans. Fans identify more 
with team, are able to feel strong emotions, interact with their team in order to escape from daily problems and routine, socialize with other fans, and seek for original and up-todate information regarding theor team. According to Budka and Jacono (2013) community is a research issue in which football be seen an activity that allow people to seek and create communities with people who actually do not belong to their private or professional social environment. Social relations in football context might be constructed and to some extend imagined across space and time to create what Benedict Anderson named "imagined community" and what Michel Maffesoli identified as "neo-tribe". Like religion, claim Giulianotti and Armstrong (1997), football involves a ritual around cultural artefacts that generate symbolic communication with performative dimensions. They have a strong commitment to their own group in everyday life by sharing their culture and lifestyle. Thus, an individual's identity is strongly connected to the collective identity of his or her group. And time passed, this individual identity will not differ to his or her everyday identity (Dal Lago \& De Biasi, 1994). One of the categories Udo Merkel (1999) used to examine football fan aspects was image. This category includes the fans' outfits, considering the trend to uniformity in the football content, stickers, flags and everyday articles one can buy at football and fan shops. Hence, they create their own fashion style and clothing production strengthens by consuming only those product and brands which symbolizes their club.

Hypothesis 7: Community engagement leads to consumer's choice cutback.

Status is defined as a higher position compared to others on some dimensions, which can be as personal skills, wealth, power, or even attractiveness, that is deemed important by society (Hyman, 1942). Our social status or how we feel our social status viewed by others, impacts our behavior in many ways. While it is evident that individuals have power, groups also have power. And the influence a group has can be directly related to the status of that group.

Looking at it from the social psychology perspectives, an individual often acts differently towards individuals in the group she belongs to, the "in-group", than she does towards individuals in other group, the "out-group", particularly when the status of the group differs. Turner (1978) believes that this is because people attach a positive value to being able to differentiate themselves from others, especially in a positive light.

Still social status remains as the one of important motivations in human behavior. For the question "why are consumers willing to pay high costs for luxury premium" costly signaling theory makes four explanations: 1) members of a group vary with respect to a 
desirable yet not directly observable quality; 2) this quality is correlated with the signal in a reliable way, which means that lower-quality individuals are not afford to emit the signal; 3) an observer derives some benefit from the possibility to discriminate between individuals with different levels of this quality; 4) signaling allows the receiver of the signal to make an inference about the sender's quality (Bousky \& Beatty, 1968). As Shin (2002) highlights people interact with others in their everyday lives and want to be seen by others as valuable and worthy. And that's why people try to manipulate their symbolic image. And by doing so they attempt to make other people evaluate their social status or wealth more favorably.

Hypothesis 8: Distinction positively moderates the relationship between community engagement and choice cutback.

Brand loyalty shows the customers long term commitment with brand and emotional attachment shows consumer's feelings, affection and passion for brands. As Loureiro et al., (2012) concluded strong brand attachment has a positive effect on brand relationship feelings.

He examined the construct attachment to brand as an antecedent to brand love feeling, and relationship between brand love and loyalty intension. The model constructed and the study was held among a group of satisfied car owners; the result concluded the feeling of love toward a brand can reinforce trust, the interest in continuing the relationship and faith in the future regarding the brand. The love feelings for a brand can strengthen trust for a brand, and when a brand or product is trusted, the person feels emotionally attached to him. Loyalty cannot be judged on the basis of trust only, but it can be judged trough love feelings towards a brand. Enhanced passion and love for a brand leads to trust and commitment.

Park et al. (2010) showed customer's higher level of emotional attachment will increase emotional dependency of customer on brand. When customers are connected with brand this connection provides comfort, happiness and security. They hypothesized and found that the more strongly consumers are attached to a brand; the more willing they are to forsake personal resources to maintain an ongoing relationship with that brand.

Similarly in the research among luxury fashion brands, scholars Thakur and Kaur (2016) examined the relationship of emotional attachment and attitudinal brand loyalty in the perspective of female consumer towards luxury fashion brands. The study concludes emotional attachment positively enhances female consumers' attitudinal brand loyalty. Thus, consumer brand relationships in luxury fashion are driven by strong emotional attachment as a strong predictor for attitudinal brand loyalty. Consumer feels more loyal to product he or she feels associated with like, love. The emotional attachment has significant 
influence on brand loyalty, hence it is hypothesized:

Hypothesis 9: Consumers with high emotional attachment stay loyal toward a brand.

Until now scholars have shown great interest on consumer brand preference studies. They conceptualized brand preference from different standpoints, examining its antecedents over different product categories and its outcomes. Some scholars (Keller, 2003; Mitchel \& Amoiku, 1985) saw brand preference as an antecedent of brand loyalty, while few of them Chang \& Ming, 2009) defined brand preference as an outcome of loyalty.

Relating brand equity as reflection of brand preference Cobb-Walgren et al. (1995) indicated that higher equity brands generate greater purchase intention. Similarly, Chang and Liu (2009) in their empirical study highlighted that higher customer brand preference was associated with more willingness to continue using the service brand. Another findings from the study on brand knowledge factors shaping brand preferences (Ebrahim et al., 2015) demonstrated the significance of consumers' experiential responses towards brands in developing their brand preferences that in turn influence brand repurchase intention.

Amir(2008) investigated the meditation effect of brand preference between advertising and customer loyalty. The result of their study confirmed positive relationship between customer brand preference and customer loyalty. As follows, it is hypothesized that:

Hypothesis 10: Consumer's preference leads to brand loyalty.

There are not much studies written on choice limitation and its outcomes, but as example of Sheena Iyengar on jam purchasing decision giving consumers with 24 flavors showed results contrary to popular belief, too many choices can be bad for sales. Customers can be attracted to a large number of choices, but when it comes to make a purchase, too many options can make decision making difficult and lead to fewer sales.

Thinking again about Apple's success in marketplace in obtaining customers' loyalty, it should be noted that in 2007 Nokia released 41 phones, Apple released only one. More of Nokia's phone required increased time and effort, and led to anxiety, regret, excessively high expectations, and self-blame when the choices didn't work. Making assumption that too many choices are often complex for consumers to be confident that they are making the right one, while choice cutback remain for customers as single perfect decision making by themselves; by gaining plenty of praise and declarations of satisfaction a satisfied consumer would become a repeat customer, it is hypothesized that: 
Hypothesis 11: Consumers with choice limitation stay loyal toward a brand.

\section{Methodology and Model Analysis}

\subsection{Research object selection and method of sampling}

A research questionnaire survey was conducted and total 227 responses were collected through the questionnaire survey of college students. Since Apple brand was chosen as a study example, to qualify the respondents, the first filter question asked the respondents to indicate the brand of mobile phone they are currently using.

In order to match condition to work with data reports on Apple smartphones, 67 response reports on other brands of mobile phone were removed (where 53 of respondents were owning Samsung smartphones, 6 participants were using LG brand, another 5 indicated Huawei as current usage brand, 2 response samples were from Nokia users, and 1 respond data was for Nokia brand).

After filtering and examining responses for inaccuracy or incomplete questionnaires, 151 questionnaires were usable. The participants ranged in age from 20 to 42, with men having higher representation $(57,3 \%)$ than women $(42.7 \%)$.

\subsection{Method of Analysis}

Reliability test using Cronbach's Alpha was implemented in order to test internal consistency. In order to avoid redundancy 4 scale items were removed in the subsequent analysis as their scores were higher when compared with other items in the same factor. Confirmatory factor analysis (CFA) was used to evaluate the psychometric properties of the study's constructs.

Convergent validity, discriminant validity, and content validity were examined using measurements such as Cronbach's alpha, Average Variance Extracted (AVE), and Composite Reliability.

\subsubsection{Reliability and Validity Testing of Constructs}

Reliability testing is conducted in order to measure the internal consistency of the measuring questionnaire. The fit indices indicate that the measurement model has good convergent validity. Cronbach's alpha for each of the scales retained ranged from 0.853 to 0.957 and composite reliability ranged from 0.63 to 0.835 .

Multiple methods have been suggested by many scholars for assessing discriminant validity. One means involves the calculation of the AVE, which measures the ratio of variance to measurement error scale. Earlier Fornell anf Larcker (1981) suggested that adequate measures 
should contain less than 50\% error variance, which means that AVE should be above 0.50 or equal. The AVE estimates for each factor in the model exceed the squared correlations between factors, suggesting discriminant validity between the scales.

As suggested Hair and his colleagues (2010) AVE of greater than 0.50 indicates that the validity both the construct and the individual variables are high. The CFA results demonstrated the overall goodness of fit of the model indices to the data: $\mathrm{CFI}=0.915 ; \mathrm{TLI}=0.90 ; \mathrm{IFI}=$ 0.917; RMSEA $=0.915 ; \mathrm{x}^{2}=568.133 ; \mathrm{df}=$ 243; $\mathrm{p}<0.000$. The measurement model was reliable and meaningful to test and assess the structural model.

\subsection{Hypotheses testing}

\subsubsection{Validity and hypotheses testing}

A structural model was tested through Structural Equation Model (SEM) using AMOS in order to examine the hypothesized relationships between 8 variables - labeling, self-image, involvement, community, emotional attachment, preference, choice cutback, and loyalty.

Structural equation modeling was chosen since, according to Hair and his colleagues
(2010), it provides a broad and integrative approach in dealing with multiple relationships while accounting for statistical efficiency. The overall fit statistics are within the acceptable ranges: $\mathrm{CFI}=0.91 ; \mathrm{TLI}=0.90$; $\mathrm{ILI}=0.911$; RMSEA $=0.094 ; x^{2}=604.632 ; d f=260 ; p<$ 0.001 . The hypothesized structural model revealed acceptable model fit (Table 5).

The results support $\mathrm{H} 1-\mathrm{H} 3$ as positive labeling is positively related to involvement $(\beta=0.80$, $\mathrm{t}=8.953, \mathrm{p}<0.001)$, self-image $(\beta=0.94$, $\mathrm{t}=12.242, \mathrm{p}<0.001)$ and community engagement $(\beta=0.89, t=9, p<0.001)$. Results on the relationship between involvement and emotional attachment was statistically significant $(\beta=$ 0.82, $\mathrm{t}=9.417, \mathrm{p}<0.001)$ giving support to H4. Self-image is positively related to brand preference $(\beta=0.22, t=3.062, P<0.05)$ in support of H6. The link between community engagement and choice cutback was significant $(\beta=0.82, t=6.956, p<0.001)$. The effects of emotional attachment on brand loyalty are not supported $(\beta=-0.03, t=-0.306, p>0.5)$. Brand preference $(\beta=0.84, t=7.072, p<$ $0.001)$ and choice cutback $(\beta=0.18, \mathrm{t}=$ 2.718, $\mathrm{p}<0.05)$ are found to have positive impacts on brand loyalty.

To analyze moderating effect of both Buzz and Distinction variables, first, the samples of

$\langle$ Table 1〉 Goodness of fit of measurement

\begin{tabular}{c|c|c|c|c|c|c}
\hline Measurements & GFI & NFI & IFI & TLI & CFI & RMSEA \\
\hline Observed & 0.785 & 0.863 & 0.917 & 0.90 & 0.915 & 0.095 \\
\hline
\end{tabular}


〈Table 2〉 Items loadings, average variance extracted, composite reliability, and Cronbach's alpha

\begin{tabular}{|c|c|c|c|c|c|}
\hline Construct & Items & $\begin{array}{c}\text { Factor } \\
\text { Loadings }\end{array}$ & AVE & $\mathrm{CR}$ & $\mathrm{CA}$ \\
\hline \multirow[t]{4}{*}{ Labeling } & & & 0.91 & 0.76 & 0.906 \\
\hline & Self-esteem1 & 0.88 & & & \\
\hline & Self-esteem2 & 0.87 & & & \\
\hline & Self-esteem3 & 0.88 & & & \\
\hline \multirow[t]{4}{*}{ Involvement } & & & 0.87 & 0.691 & 0.899 \\
\hline & Involvement2 & 0.798 & & & \\
\hline & Involvement3 & 0.857 & & & \\
\hline & Involvement4 & 0.838 & & & \\
\hline \multirow[t]{4}{*}{ Self-Image } & & & 0.926 & 0.807 & 0.926 \\
\hline & Self-Image1 & 0.884 & & & \\
\hline & Self-Image2 & 0.929 & & & \\
\hline & Self-Image3 & 0.882 & & & \\
\hline \multirow[t]{4}{*}{ Community } & & & 0.836 & 0.63 & 0.874 \\
\hline & Community3 & 0.766 & & & \\
\hline & Community4 & 0.804 & & & \\
\hline & Community5 & 0.81 & & & \\
\hline \multirow[t]{4}{*}{ Emotional Attachment } & & & 0.887 & 0.725 & 0.883 \\
\hline & EmotionalAttachment1 & 0.858 & & & \\
\hline & EmotionalAttachment2 & 0.885 & & & \\
\hline & EmotionalAttachment3 & 0.809 & & & \\
\hline \multirow[t]{4}{*}{ Preference } & & & 0.938 & 0.835 & 0.951 \\
\hline & Preference1 & 0.87 & & & \\
\hline & Preference2 & 0.931 & & & \\
\hline & Preference3 & 0.938 & & & \\
\hline \multirow[t]{4}{*}{ Choice cutback } & & & 0.842 & 0.641 & 0.853 \\
\hline & ChoiceCutback1 & 0.699 & & & \\
\hline & ChoiceCutback2 & 0.829 & & & \\
\hline & ChoiceCutback3 & 0.864 & & & \\
\hline \multirow[t]{5}{*}{ Loyalty } & & & 0.947 & 0.816 & 0.945 \\
\hline & Loyalty1 & 0.902 & & & \\
\hline & Loyalty2 & 0.925 & & & \\
\hline & Loyalty3 & 0.928 & & & \\
\hline & Loyalty 4 & 0.856 & & & \\
\hline \multirow[t]{6}{*}{ Buzz } & & & & & 0.909 \\
\hline & Buzz1 & & & & \\
\hline & Buzz2 & & & & \\
\hline & Buzz3 & & & & \\
\hline & Buzz4 & & & & \\
\hline & Buzz5 & & & & \\
\hline \multirow[t]{5}{*}{ Distinction } & & & & & 0.897 \\
\hline & Distinct1 & & & & \\
\hline & Distinct2 & & & & \\
\hline & Distinct3 & & & & \\
\hline & Distinct4 & & & & \\
\hline
\end{tabular}

Note: $\mathrm{AVE}=$ Average Variance Extracted, $\mathrm{CR}=$ Composite Reliability, $\mathrm{CA}=$ Cronbach's Alpha 
Buzz and Distinction variables were divided each into two groups by using median split (high and low). Multi-group analysis with chisquare difference test was used to examine the moderating effect of Buzz on the relationship between Involvement and Emotional Attachment, and moderating effect of Distinction on the relationship of Community and Choice Cutback. Before the given relationship was analyzed, constrained model and unconstrained models were compared. After the chi-square test was used to compare the 2 models. The results are shown in the following tables.

The results indicate that Buzz positively moderates the relationship between involvement and emotional attachment. In that, High Buzz and Low Buzz demonstrate differences, these differences are confirmed by chi-square difference test result (13.184) and $\mathrm{p}$-value, which is significant, giving support for $\mathrm{H} 5$.

The findings demonstrate that Distinction does not moderate the relationship between Community engagement and Choice Cutback. Though two categorical groups of distinction

〈Table 3〉 Goodness of fit of the final research model

\begin{tabular}{c|c|c|c|c|c|c}
\hline Measurements & GFI & NFI & IFI & TLI & CFI & RMSEA \\
\hline Observed & 0.78 & 0.854 & 0.911 & 0.90 & 0.91 & 0.094 \\
\hline
\end{tabular}

$\langle$ Table 4〉 Structural model assessment of direct relationship

\begin{tabular}{c|l|r|r|r|r|r}
\hline Hypothesis & \multicolumn{1}{|c|}{ Relation } & Beta & SE & T-value & p value & Findings \\
\hline H1 & Labeling $\rightarrow$ Involvement & 0.80 & 0.09 & 8.953 & $* * *$ & Supported \\
\hline H2 & Labeling $\rightarrow$ Self-Image & 0.94 & 0.085 & 12.242 & $* * *$ & Supported \\
\hline H3 & Labeling $\rightarrow$ Community Eng. & 0.89 & 0.089 & 9 & $* * *$ & Supported \\
\hline H4 & Involvement $\rightarrow$ Emot.Attach. & 0.82 & 0.084 & 9.417 & $* * *$ & Supported \\
\hline H6 & Self-Image $\rightarrow$ Preference & 0.22 & 0.075 & 3.062 & $*$ & Supported \\
\hline H7 & Communityt Eng. $\rightarrow$ Choice Cutb. & 0.82 & 0.132 & 6.956 & $* * *$ & Supported \\
\hline H9 & Emot.Attach. $\rightarrow$ Loyalty & -0.03 & 0.119 & -0.306 & 0.76 & Not supported \\
\hline H10 & Preference $\rightarrow$ Loyalty & 0.84 & 0.107 & 7.072 & $* * *$ & Supported \\
\hline H11 & Choice Cut. $\rightarrow$ Loyalty & 0.18 & 0.063 & 2.973 & $*$ & Supported \\
\hline$* * *: \mathrm{p}<.001$ & $*<.05$ & & &
\end{tabular}

〈Table 5〉 Testing Moderating Effect for Buzz

\begin{tabular}{lll|c|c|c|c}
\hline & & Estimate & S.E. & C.R. & P \\
\hline Buzz $($ High $)$ & $\rightarrow$ & Involvem*Emot.Attach & 0.592 & 0.132 & 4.478 & $\langle 0.001$ \\
\hline Buzz $($ Low $) \rightarrow$ & Involvem*Emot.Attach & 0.829 & 0.234 & 4.485 & $\langle 0.001$ \\
\hline
\end{tabular}


〈Table 6〉 Testing moderating effect of Buzz on Involvement*Emotional Attachment

\begin{tabular}{l|c|c|c|c|c}
\hline & $\begin{array}{c}\text { Constrained } \\
\text { Model }\end{array}$ & $\begin{array}{c}\text { Unconstrained } \\
\text { Model }\end{array}$ & Differences & $\begin{array}{c}\text { Result on } \\
\text { Moderation }\end{array}$ & $\begin{array}{c}\text { Result on } \\
\text { Hypothesis }\end{array}$ \\
\hline Chi-Square & 64.006 & 50.822 & 13.184 & \multirow{2}{*}{ Significant } & \\
\cline { 1 - 4 } $\mathrm{df}$ & 32 & 26 & 6 & 0.04 & \\
\hline $\mathrm{p}$-value & \multicolumn{3}{c}{ The hypothesis statements } & Supported \\
\hline \multicolumn{7}{c}{ H5: Buzz positively moderates the relationship between consumer } \\
involvement and emotional attachment.
\end{tabular}

$\langle$ Table 7〉 Moderation test for Distinction

\begin{tabular}{lll|c|c|c|c}
\hline & & Estimate & S.E. & C.R. & P \\
\hline Distinction (High) $\rightarrow$ & Commit.*Choice cutback & 0.598 & 0.185 & 3.916 & $\langle 0.001$ \\
\hline Distinction (Low) $\rightarrow$ Commit.*Choice cutback & 0.449 & 0.374 & 1.787 & 0.074 \\
\hline
\end{tabular}

〈Table 8> Testing moderating effect of Distinction on Community*Choice Cutback

\begin{tabular}{|c|c|c|c|c|c|}
\hline & $\begin{array}{c}\text { Constrained } \\
\text { Model }\end{array}$ & $\begin{array}{l}\text { Unconstrained } \\
\text { Model }\end{array}$ & Differences & $\begin{array}{l}\text { Result on } \\
\text { Moderation }\end{array}$ & $\begin{array}{l}\text { Result on } \\
\text { Hypothesis }\end{array}$ \\
\hline Chi-Square & 148.133 & 136.859 & 11.274 & \multirow{3}{*}{ Significant } & \\
\hline df & 45 & 38 & 7 & & \\
\hline $\mathrm{p}$-value & & & 0.127 & & \\
\hline \multicolumn{5}{|c|}{$\begin{array}{c}\text { The hypothesis statements } \\
\text { H8: Distinction positively moderates the relationship between community } \\
\text { engagement and choice cutback. }\end{array}$} & Not supported \\
\hline
\end{tabular}

show differences, regression coefficients are close (estimates for High Distinction $=0.598$, estimates for Low Distinction $=0.449$ ). Insignificance of moderation effect of Distinction is proved by chi-square (0.127) and p-value, which is higher 0.05 and provides weak evidence.

\subsubsection{Final Model}

The given results support H1, H2 and H3 as positive labeling leads to involvement, selfimage construction and community engagement. Thus, proving that labeling affects reaction and that it is common for the individual to incorporate that label into his or her own selfconcept. Unlike with negative labeling, individuals labeled in positive term does not feel shunned, mostly they are forced to integrate into society or build social groups. The results also support $\mathrm{H} 4$ and $\mathrm{H} 5$ as it was suggested, demonstrating 
that buzz impacts a full range of emotions generating response. Since buzz mainly based on happy feelings and trust, it establishes a pleasant associations and memories about a brand in customer's mind. The link between Self-Image and Preference is partially supported (H6). Considering that previous research results proved the direct effect of brand preference to brand loyalty as its antecedent, H10 is fully supported. Results for H7 is also significant demonstrating that Community positively influences Choice Cutback, while H11 suggesting the direct relationship between Choice Cutback and Brand Loyalty is partially supported. The results rejected $\mathrm{H} 8$ and $\mathrm{H} 9$. The reason of relationship insignificancy between Emotional Attachment and Brand Loyalty can be explained through psychological model of attachment theory. In John Bowlby's (1982) theory attachment was described as dynamics of long-term and shortterm relationship. And individuals' emotional attachment is measured by the degree to which an individual views the given relationship. Park and his colleagues (2006) defined emotional brand attachment as the nature of emotional reaction and the unique elements associated with this reaction as a self-connection with the brand and as a readiness to respond.
Holmes (2000), Reis and Patrick (1996) make similar conclusion claiming that such self-linkages impacts one's readiness to allocate processing resources to the brand. Emotional attachment found to induce desire for the brand, satisfaction with its acquisition, and hope for its suture acquisition (Mikulincer et.al., 2001). Since emotion goes through the attitude and particular beliefs, it was suggested and analyzed that Emotional Attachment indirectly leads to brand loyalty through brand preference. The results from analysis gave significant support for this suggestion $(\beta=0.71, t=8.442, p<0.001)$.

The moderation effect of Distinction on the relationship between community and choice limitation is not supported. This suggests that people buy Apple's IPhone mostly because of its market share, which limits their choice on mobile phone. Apple and Samsung capture almost all the smartphone market (Apple 14,4\% 2017, 15.1 - 1Q2018; Samsung 22,7\% - 2017, $22 \%$-1Q2018) leaving only few competitors in marketplace. Hence, most consumers influenced by social factors, such as the consumer's small groups, family, and social roles and status tend to buy Apple's products.

〈Table 9〉 Testing direct relationship between Emotional Attachment and Preference

\begin{tabular}{c|c|c|c|c|c}
\hline Relation & Beta & SE & t-value & p-value & Findings \\
\hline Emotional.Attach. $\rightarrow$ Preference & 0.71 & 0,103 & 8.442 & $* * *$ & Supported \\
\hline
\end{tabular}




\section{Conclusion and Implications}

\subsection{Summary}

Previous studies have predominantly focused on negative labeling of individuals in areas as psychology, criminal and/or deviance, uncovering a range of negative outcomes, such as discrimination, stereotyping, self-isolation and/ or rivalry. Despite positive labeling can generate attention for brands and provide consumers with identity and community commitment, not much studies have been done in marketing perspective. This study tries to show positive effects of labeling. Analyzing data collected through survey questionnaire, it was found that positive labeling leads to brand loyalty among customers and can be avenue to accomplish one of marketing's main objectives, which is the development of distinctiveness for brands and consumers.

It is common that ad slogans of firm is confused by consumers with the companies' mission statements, with their goals and objectives. Ad slogans are recognized as company's culture or guiding principle and appears as a part of brand image. Slogans represent a brand's personality and founding idea or beliefs by carrying strong and complex emotional concept which provides a message for consumers. In order to check people's responsiveness and susceptibility toward positive labeling the first part of the survey questionnaire asked respondents to evaluate, using scale that ranged from 1 Strongly Disagree to 7 - Strongly Agree, their perceptiveness of ad slogans with content of labeling (Appendix 1 - "Soon there will be 2 kinds of people. Those who use computers, and those who use Apples"; "Here to the Crazy Ones"; "A brand's best friends"). In evaluating the given slogans as Apple company's messages respondents rated each indications highly, as can be seen in the Table 13, supporting suggestion that people like to be labelled positively and they attach those labels to themselves acting and thinking according to tags.

When people hear slogans they try to relate to these phrases and painting themselves. Words have the power to influence human emotions, simple but profound message sounded cheery and optimistic make customers connect to the brand emotionally giving them a reason to want to add your brand to their identity. Since ad slogans stick in consumers' mind.

By labeling consumers in positive aspect customers benefit from it through increased consumer group distinctiveness, which is fundamental need and a cornerstone of a positive self-image and self-esteem. When consumers engage in community and signifies their own group, it helps them to boost their identity by defining the ingroup against outgroup, and setting their group apart others. Hence, it can lead to increase of brand identification. And it is suggested that being in community consumers can get product value in the terms of enhanced 
group distinctiveness. Building uniqueness among its consumers, company helps customers in highlighting differences between brands.

Two sentences were given to the respondents to evaluate their perception toward brand's role with the rating scales ranged from 1 Strongly Disagree to 7 - Strongly Agree. Results demonstrate consumers believe that brands lead them toward new shapes of self and forms of their being and doing and that brands create customers (Table 11). The findings seem to suggest that when customers perceive that the brand helps to get a certain image, they will be loyal to that brand. This finding is consistent with the premise that customers purchase not only goods, but also the image that a brand offers. An image that build customers is important for them, because it puts them in a different (mostly superior) position from others, reflecting their social status and predilection for high quality. Concluding that self-concept plays an important role in determining consumers' choice and consumers prefer brands which has images appropriate with their perceptions of self. Findings of this study confirm reiteratively that both self-image and brand preference appear to be strong predictors of brand loyalty.

This research advances in showing that both labeling and social identification transfer positive effects consumer's preferences for the brand. This puts the role of the labeling into a new perspective, indicating being tagged is more than liked condition, it consequentially becomes a part of consumers' identity.

The current research has shown the importance

〈Table 10〉 Respondents' responsiveness level toward messaging in ad slogans

\begin{tabular}{l|r|r|r|r|r|r|r}
\hline & \multicolumn{1}{|c|}{1} & \multicolumn{1}{c|}{2} & \multicolumn{1}{c}{3} & 4 & 5 & 6 & 7 \\
\hline Cheerful & $0.7 \%$ & $4 \%$ & $8.7 \%$ & $22.7 \%$ & $40.7 \%$ & $20 \%$ & $3.3 \%$ \\
\hline Imaginative & - & $1.3 \%$ & $13.3 \%$ & $26.7 \%$ & $34.0 \%$ & $21.3 \%$ & $3.3 \%$ \\
\hline Charming & - & $2.7 \%$ & $12.7 \%$ & $27.3 \%$ & $36.7 \%$ & $17.3 \%$ & $3.3 \%$ \\
\hline Spirited & $0.7 \%$ & $1.3 \%$ & $12.7 \%$ & $20.7 \%$ & $38.7 \%$ & $21.3 \%$ & $4.7 \%$ \\
\hline Reliable & $2 \%$ & $3.3 \%$ & $12 \%$ & $38 \%$ & $28.7 \%$ & $14.7 \%$ & $1.3 \%$ \\
\hline Successful & - & - & $6 \%$ & $22 \%$ & $32.7 \%$ & $31.3 \%$ & $8 \%$ \\
\hline
\end{tabular}

〈Table 11〉 Respondents' perception toward brand

\begin{tabular}{l|c|c|c|c|c|c|c}
\hline & 1 & 2 & 3 & 4 & 5 & 6 & 7 \\
\hline $\begin{array}{l}\text { Brands lead customers toward new } \\
\text { shapes of self, and toward new }\end{array}$ & - & $2 \%$ & $8.7 \%$ & $15.3 \%$ & $43.3 \%$ & $28 \%$ & $2.7 \%$ \\
forms of being and doing & - & $4 \%$ & $4.7 \%$ & $26 \%$ & $28.7 \%$ & $28 \%$ & $8.7 \%$ \\
\hline Brands Create Customers & & - & & & & \\
\hline
\end{tabular}


of customer labeling in significantly motivating customers to have brand loyalty. Going back to Apple's "Get a Mac" campaign, this example demonstrates that the product you use signifies the kind of person you are. Another example is that Apple did not ask their customers which type of iPod they preferred or liked the best, they sold iPod by asking "Which iPod are you?". Identity is an important psychological and social concept that relates to how an individual view and define himself and others, identity in branding suggests that consumers build their identities and present themselves to others through the brands they choose. Consumers choose certain brand products because they see themselves or they want other people to view them in a particular way.

\subsection{Implications and Limitations}

\subsubsection{Managerial implications}

Developing and maintaining a loyal customer base is viewed as the single most important driver of long-term financial performance. So this study is viewed to help the managers to establish an efficient loyalty programs.

This study demonstrates that developing involvement and community engagement and building image for customers can increase the level of brand loyalty. The findings should prompt managers to reconsider the element of positive labeling in marketing and see the relationship with brand loyalty as a possible opportunity. While previous research has focused on the negative aspects of labeling, certain brands may wish to take a more active role in the promotion of labeling using in building marketing strategies. Brand managers could encourage a sense of social identity between consumers through personalization of their brand and social comparison of their customers. Nowadays many scholars agree that mass consumption is becoming a part of the past. Consumers of these days want to feel that products are authentically made and designed especially for them. This increases feelings of uniqueness and individuality among customers, and allows positive brand associations.

Not only companies could benefit from labeling, customers also can take advantages from being positively labeled. Labeling in positive call tends to motivate people to take action and make change in their life. Often companies use engagement strategies to create an interaction with customers as a business and a brand. But it is important for companies to demonstrate their interest in customers' life experience and success. Unlike most listening centers of firms, using social media as a conversational tool connected with other consumer members helps companies to get consumers' trust. For example, providing convenience for brand consumers to build their presence by creating own site for speaking opportunities or webinars cements trust toward a brand. 
In daily living by loyalty we mean friendship and trust. Addressing customers in right terms and treating them as friends is a concept that brings successful business-customer relationship. Taking the same principles, such as support and encouragement into a firm's business basis would enable managers achieve a mutual relationship for long term. Because nowadays customers have wide variety of choice they tend to be savvy, and to choose only those brand to which they feel trust and respect. Friendship relationship strategy can bridge emotional gap finding a good balance to keep customers happy and excited about their choice.

As it was concluded in the discussion part, mostly, customers' choice of brand is based on their emotions, how they feel and see themselves, and their relationship with the people around, than on the superiority of a company's products. And there is a need for marketers to focus on their customers' emotions and identities equally with their products' unique features and qualities. Doing so companies can build brands that involves customers' affection.

\subsubsection{Limitation and direction for further research}

The following suggestions for future research arise from the limitation of the given study. In this research, the sample was limited by university students, mostly people in their twenties (90\%). Though some scholars such as Basil (1996),
Berkowitz-Donnerstein (1982), and Coutright (1996) argues that even student samples are legitimate ways to efficiently explore theoretical relationships. Shapiro (2002) examining reflexive psychological process claimed that there is no significant difference among adult respondents, and student samples can be valuable exploratory vehicle in examining social behaviors. However, future research should expand the sample to include people from various social strata as well as from different age group in order to test generalizability of student samples.

This study analyzed labeling messages and its perception among customers Apple brand as a case study, the findings might not be generalizable to other brands or product categories. Thus, it would be interesting to expand the research to other industries and brands and also weigh the positive against the negative consequences. In order to give result more weight Taking into consideration findings from previous researches labeling and community engagement can be seen as double-edged sword with ambivalent effect. Brand communities can yield maximum benefit for a company, but at the same time, being a fundamental aspect of the brand it can cause harm to companies by switching to another brand. More research is needed to understand how the effects can be balanced.

The survey data collection was done in Korea, in the country with collective culture, where people stress the importance of community and have strong sense of solidarity and belonging. 
As it is commonly known members of collectivist society are associated with low relational mobility, which means that bound relationships are stable, strong and long-lasting (Kito M., et.al., 2017). This kind of relationships are formed due to factors rather than by their personal choice. Unlike with collectivism society, people of individualistic society prioritize their self and behave independently from group interests. In individualist societies a person's self-concepts are focused on personal values, and individuals tend to describe themselves in terms of their unique personal characteristics and traits (Markus H.R., Kitayama S., 1991). Since how people shop, dress, and make decisions all are influenced by whether they are from a collectivist or individualist culture, future research should be done in countries with individualistic culture to compare effects of labeling.

It could be interesting for further research to consider other factors, such as brand heritage, prestige of brand, and sense of shared value as direct antecedents of brand loyalty. It would be interesting to examine brand forgiveness and choice cutback as outcomes of brand loyalty.

However, the manner how the study was conducted and data was collected remains as the most important limitation. The given study conducted through analyzing survey questionnaires, while the main disadvantage of questionnaires is that respondents have to fit their answers into what is on offer. Another weakness of questionnaires is low response rate: respondents can give incorrect answers or uncompleted samples, which leads to inaccurate data. Thus, it is important for applied research to be conducted for better understanding psychological factor affecting consumer behavior, giving an opportunity to respondents to express themselves in the way they want.

〈Received October 4. 2018〉 $\langle$ Accepted February 13. 2019〉

\section{References}

Aaker D. A., 1996, "Building Strong Brands," Free Press, New York, NY, pp. 138-141. Aaker D. A., 1997, "Dimensions of brand personality," Journal of Marketing Research, 34-3, pp.347-356.

Aaker, D. A., 2003, "The power of the branded differentiator" MIT Sloan Management Review, 45-1, pp.83-87.

Abrams D., 1990, "Social identity theory," Hertfordshire: Harvester Wheatsheaf.

Adams M. S., Robertson C. T., Gray-Ray P., Melvin C., 2003, "Labeling and Delinquency," Adolescence, 38-149, pp.171-186.

Amir O., Levav J., 2008, "Choice construction versus preference construction: The instability of preferences learned in context," Journal of Marketing Research, 45-2, pp.145-158.

Bagozzi R. P., 1982, “A field investigation of causal relations among cognitions, affect, 
intentions, and behavior," Journal of Marketing Research, 19-4, 562-683.

Bagozzi R. P., 1983, “A holistic methodology for modeling consumer response to innovation," Operations Research, 31-1, pp.128-176.

Bailey R., Ball, S., 2006, “An exploration of the meanings of hotel brand equity," The Service Industries Journal, 26(1), pp.1538.

Bauer, H. H., Stockburger-Sauer N. E., Exler, S., 2008, "Brand image and fan loyalty in professional team sport: a refined model and empirical assessment," Journal of Sport Management, 22-2, pp. 205-226.

Bendapudi N., Berry L. L., 1997, 'Customers' motivations for maintaining relationships with service providers," Journal of Retailing, 73-1, pp.15-37.

Bhattacharya C. B., Elsbach K. D., 2002, "Us versus them: The roles of organizational identification and disidentification in social marketing initiative," Journal of Public Policy \& Marketing, 21-1, pp.26-36.

Bowker A., 2006, "The relationship between sports participation and self-esteem during early adolescence," Canadian Journal of Behavioral Science, 38-3, pp. 214-229.

Butcher K., Sparks B., O’Callaghan F., 2001, "Evaluative and Relational Influences on Service Loyalty," International Journal of Service Industry Management, 12-4, pp. 310-27.

Carroll B. A., Ahuvia A. C., 2006, "Some antecedents and outcomes of brand love," Marketing Letters, 17-2, pp.79-89.

Civilia L., Munyaradzi W. N., Lester W. J., 2016, "Antecedents of consumer brand engagement and brand loyalty," Journal of Marketing Management, 32, pp.558578.

Chang, P. L. \& Chieng, M. H. 2006, "Building consumer - brand relationship: A crosscultural experiential view," Psychology \& Marketing, 23-11, pp.927-959.

Chiricos T., Barrick K., Bales W., Bontrager S., 2007, "The Labeling of Convicted Felons and Its Consequences for Recidivism," Criminology, 45, pp.547-581.

Christopher J. B., Carol S. D., Lee R., Aaron C. K., Natalia O. M., 2008, "Political mindset: Effects of schema priming on liberalconservative political positions," Journal of Experimental Social Psychology, 45 pp. 890-895.

Dawar, N., Bagga, C. K., 2015, “A better way to map brand strategy," Harvard Business Review, 93-6, pp.90-97.

Devlin J. F., Gwynne A. L., Ennew C., 2002, "Antecedents of service expectations," The Services Industries Journal, 22-4, pp.117131.

Dickson P. R., James L. G., 1987, "Market Segmentation, Product Differentiation, and Marketing Strategy," Journal of Marketing, 51-2, pp.1-10.

Fornell C., Larcker D. F., 1981, "Evaluating 
structural equation models with unobservable variables and measurement error," Journal of Marketing Research, 18, pp.39-50.

Gladden J., Funk, D., 2001, “Understanding brand loyalty in professional sport: examining the link between brand associations and brand loyalty," International Journal of Sports Marketing \& Sponsorship, 3-1, pp. 67-91

Haire M., 1950, "Projective Techniques in Marketing," Journal of Marketing, 14, pp. 649-665.

Lloyd C. H., 2004, "The four levels of loyalty and the pivotal role of trust: A study of online service dynamics," Journal of Retailing, 80-2, pp.139-158.

Nathaniel D. L., Hanks L., 2017, “The other customer: The impact of self-image in restaurant patronage," Journal of Foodservice Business Research, 20-3, pp.268-285.

Rakhi T., 2016, "Understanding Customer Engagement and Loyalty: A Case of Mobile Devices for Shopping," Journal of Retailing and Consumer Services, 32, pp. 151-163.
Rundle-Thiele S., 2005, "Exploring loyal qualities: assessing survey-based loyalty measures," Journal of Services Marketing, 19-7, pp. 492-500.

Schifferstein H. N., Zwartkruis-Pelgrim E. P., 2008, "Consumer-product attachment: Measurement and design implications," International Journal of Design, 2-3, 1-13. Sirgy M. J., 1982, "Self-Concept in Consumer Behavior: A Critical Review," Journal of Consumer Research, 9-3, pp.287-300

Tax S. S., Murali C., Christiansen T., 1993, "Word-of-mouth in consumer decision making: An agenda for research," Journal of Consumer Satisfaction, Dissatisfaction and Complaining Behavior, 6, pp.74-80.

Williams J., Chinn S. J., 2010, "Meeting relationship-marketing goals through social media: a conceptual model for sport marketers," International Journal of Sport Communication, 3-4, pp. 422-437.

Yoo B., Donthu N., Lee S., 2000, "An examination of selected marketing mix elements and brand equity," Journal of the Academy of Marketing Science, 28-2, pp. 195-211. 